\title{
An operational support approach for Mining Unstructured Business Processes
}

\author{
Zineb Lamghari $^{1 *}$, Maryam Radgui ${ }^{1,2}$, Rajaa Saidi $^{1,2}$, Moulay Driss Rahmani ${ }^{1}$
}

\begin{abstract}
The refined process mining framework contains a set of activities that use extracted information from event logs, discovered models and normative ones. Among these activities, we find those dealing with running events in a Structured Business Process (SBP) context, which are the Detect, the Predict and the Recommend activities. These three activities are nominated as operational support system that performs well on SBP while, it stills a challenging task for an Unstructured Business Process (UBP), because of its complex structure. In this regard, a special interest is given to the use of existing process mining techniques to analyse unstructured processes, from the extraction of a process model based on event data to recommendations at a later stage. To this end, we propose the orchestration of process mining activities into an UBP operational support approach, through the following phases: 1.Preparing Normative model, 2.Detect violations, 3.Preparing predictive model and Predictions and 4.Preparing the recommender model and Recommendations.

Keywords: Process mining - Operational support - Unstructured Business Processes - Structured Business Process - Structuring techniques - Prediction - Recommendation - Heuristics Miner - BPMN

${ }^{1}$ LRIT associated unit to CNRST (URAC 29) Rabat IT Center Faculty of Sciences, Mohammed V University in Rabat, Morocco

${ }^{2}$ SI2M Laboratory, National Institute of Statistics and Applied Economics, Morocco

*Corresponding author: zineb_lamghari2@um5.ac.ma

DOI: http://dx.doi.org/10.22456/2175-2745.106277 • Received: 30/08/2020 • Accepted: 07/12/2020

CC BY-NC-ND 4.0 - This work is licensed under a Creative Commons Attribution-NonCommercial-NoDerivatives 4.0 International License.
\end{abstract}

\section{Introduction}

Process mining aims at discovering, monitoring and improving real processes by extracting knowledge from event logs. Basically, its types are: Discovery (takes an event log and produces a model), Conformance Checking (compares the existing model to event logs of the same model and checks if it corresponds to reality, as recorded in the $\log$ ) and Enhancement (an existing process model using information about the actual process, recorded in some event log, for improvement). Further, the recent refined process mining framework [1] extends these types into three categories with ten activities, which are: Navigation (Discovery, Enhance and Diagnosis), Auditing (Detect, Check, compare and Promote) and Cartography (Explore, Predict and Recommend). These activities link current and historic data to the de jure model (a normative model that specifies how things should be done or handled) and the de facto model (a control-flow model that represents the order in which process model activities must be executed). However, the most challenging task is how current situations benefit from historic data.

To this purpose, operational support systems have been defined, to learn from existing structured models, normative ones, historic and current/running data. Thus, the use of the Detect, the Predict and the Recommend activities is manda- tory. Also, the appearance of the predictive (aims at predicting an outcome that can influence next events) and the recommender models (aims at defining the "preference" that can be attributed to an activity or a resource) is crucial. These two models are considered as inference ones. Here, operational support approaches perform well with SBP, while they still a challenging task for UBP. In this respect, the [2, 3, 4, 5, 6] demonstrate the still encountered issues related to the UBP operational support application. This is justified by their unpredictability, flexibility, and complexity. In this sense, an UBP can be defined as a spaghetti or a knowledge-intensive process that can have a start event, but activities and tasks are not necessarily consistent and the end state is not predefined. Therefore, it is required to simplify unstructured processes. Beyond, our problematic consists in constructing an operational support approach for UBP. In this context, we discuss the Buijs hypothesis ${ }^{1}$.

Buijis [7] presents briefly how the process mining activities re-organization can provide an operational support for UBP, based on the structured BP version, i.e., reducing the UBP complexity. This operation necessitates the intervention of other process mining activities as Diagnosis, Check, Promote,

\footnotetext{
${ }^{1}$ This point has been discussed in the online futurelearn process mining courses https://www.futurelearn.com/courses/process-mining/7/steps/215532
} 
etc. Hence, the order of process mining activities stills a questionable task. To this end, our paper objective is to establish an operational support approach that deals with UBP, i.e., detects violations, predicts events and recommends actions for unstructured BPs at runtime. So, we suggest to combine, in a specific order, the ten activities of the refined process mining framework.

Tackling the analysis of UBP through the orchestration of existing process mining activities, by necessity techniques, brings new knowledge to the research field in terms of producing a complete approach that can handle the analysis, the discovering, the prediction and the recommendations actions. Therefore, our paper is organized as follows: Section 2 introduces the still encountered issues related to operational support approaches. Section 3 presents techniques that will lead us to treat unstructured BPs. In addition, section 3 explores recent methods and techniques of BP prediction, UBP simplification, UBP structuring and event logs auditing. Section 4 details our UBP operational support approach phases. In section 5, a concrete example is depicted to simulate our approach. Conclusion and further directions are presented in section 6 .

\section{Related works}

In this section, we discuss the still encountered issues related to operational support approaches. We investigate this point from the process mining view [8]. In this context, several approaches have been developed. Since Process Mining Manifesto released at the end of 2011, we focused on research papers published from the beginning of 2012 year:

The [9] developed a concrete implementation of operational support meta-model, based on the workflow system Declare and the ProM framework. This meta-model treats four types of queries: simple queries, compare queries, predict queries, and recommend queries.

The [10] proposed a global approach that learnt discovered behaviours to predict the classes of visible and invisible traces. The discovered signature patterns allow the distinction between various classes of behaviour and by necessity related business conditions.

The [11] suggested a method that predicts process risks by applying decision trees to the logs of previous process executions, taking into account multi-perspectives of process mining like: process data, used resources, task durations, and contextual information. To do so, the proposed method helps the process participants to make risk-informed decisions. Likewise, the [12] explored an approach that forecasts the remaining processing time, and recommend activities to reduce risks.

The [13] illustrated a method that can prevent the undesirable behaviour from occurring in next executions. This is done based on the Markov cluster (MCL) algorithm with the ability to detect changes of a process according to the selected perspectives. .

The [14] presented framework for predicting dynamic be- haviour from event logs. It is capable of correlating and clustering dynamic behaviour. The framework allows the prediction of the executor of a certain activity, the remaining time to the end of the process instance, the next activities to work on, and the outcome of the executions of process instances. The [15] demonstrated a multi-stage deep learning approach for BP event prediction that aims at predicting the next business process event, considering the execution of log data from the previously completed process instances. This is done to predict the business process events, to initiate timely interventions for undesired deviations from the desired workflow.

The [16] proposed a framework for detecting and analysing, at runtime, business process deviances, which leverages both a novel incremental approach to the discovery of an ensemblebased deviance detection model.

Moreover, the [17] established a method that addresses the problem aiming at learning the impact of past events on the future events using deep learning methods. It is a deep predictive model for multi-attribute Event Sequence.

On one hand, all the cited papers reported on the application of process mining for operational support, do not use the orchestration of the whole existing process mining activities (Discover, Explore, Check, Compare, Promote, Diagnose, Enhance, Detect, Predict and Recommend). On the other hand, some of them only generate operational support to structured BPs.

\section{Required techniques for providing op- erational support}

Executing loosely structured processes generate unstructured behaviours. They are difficult to be analysed and hard to be understood, due to its complex structure. In particular, during the application of operational support systems for detecting violations, predicting events, and recommending actions. In this respect, the transformation of an UBP into a more structured process model is crucial. Therefore, we must use: process discovery algorithms (for simplification), structuring techniques (for structuring process models), auditing techniques (for obtaining refined models and detecting violations) and predictive BP methods (for defining predictions and recommending actions).

For this purpose, the current section presents related techniques to provide operational support. To do so, we discuss : predictive BP methods, simplification, structuring and auditing techniques.

\subsection{Predictive business process model}

The ability to know in advance the trend of running process instances, with respect to different features, such as the expected completion time, would allow business managers to timely counteract to undesired situations, in order to prevent losses. In this context, techniques focusing on predicting remaining time can influence other predictive business monitoring dimensions. This is mentioned in different research papers such as [18], where the authors present predictive dimensions into: 
categorical, numerical and hybrid predictions. In this regard, predicting the remaining time, to accomplish an activity, helps respectively to predict next events and suitable resources for executing activities. In this sense, a considerable number of methods have been put forward to address the remaining time dimension.

In this sense, we cannot provide a comprehensive overview of the whole prediction techniques. Therefore, we select one predictive method, related to the remaining time dimension, from the integrated list, published in $[18,19,20]$. Among this list, we find this method [21]. We considered it as a proofof-method choice to test time impact on the other predictive business monitoring dimensions. This method reflects the easy availability of the software tools and the scientific advantages. This is done by learning from one half of the event log and evaluating using the other half.

\subsection{Selecting the audit approach}

Auditing exists in different context (financial, maintenance engineering practices, health safety issues, ethical conduct, etc.). Here, we are interested in the context of auditing business processes against documented procedures. Actually, this is released using process mining concept. Nonetheless, audits are rarely supported by process mining tools in practice. The basic approach is mentioned within the refined process mining framework [8] in 2016, where the audit activities are applied on structured BPs. The latest version of the auditing framework is edited in 2018 [22]. This approach uses an initial normative model for monitoring and rectifying the discovered process model or the de facto model, to produce a simplified one. By doing so, an audit report is obtained. However, none of the previous works have demonstrated how to refine the initial normative model, using the combination between frequency paths concept [23] and the simplified BP form of an UBP. Therefore, we propose to combine between the latest auditing version and the frequency paths concept (approach detailed in sub-section 5.1).

The frequency concept aims at discovering possible process models according to frequent execution paths percentage. This helps in paths optimization, performance improvement and resources management.

To do so, our approach presents the monitoring report that includes historic event logs analysis. This will help in predicting future events in an operational support system.

\subsection{Process Discovery algorithm}

There are several process mining techniques available as PROM plug-ins [24]. In fact, we are looking for techniques that process data in real time. In this sense, the most robust and commonly used discovery algorithms are: heuristics miner and fuzzy miner. Heuristics miner algorithm [25] produces an abstracted process model (heuristics net) based on the frequency of activities. This represents main behaviours in unstructured processes. Similarly, fuzzy miner algorithm [26] reduces the complexity detected in a process model by highlighting significant information and ignored less signif- icant activities (fuzzy model). Fuzzy models are limited by the conversion condition to others process modelling types, while heuristics nets can be converted to different notation like BPMN, C-Net, etc. To this end, we select heuristics miner as the process discovery algorithm for obtaining a simplified process model representation.

\subsection{Structuring techniques}

The structuring techniques are based on the following four studies of $[27,28]$ and $[29,30]$. The first two approaches treat only unstructured acyclic rigid fragments with parallelism. The second two approache deal only with rigid fragments without parallelism (exclusive gateways). This gap requires a hybrid approach that combines between the two aforementioned rigid fragments categories. To do so, the recent approach of [31] is applied. This later represents a discover-and-structure method for generating a SBP from event logs. This method builds upon the hypothesis: instead of attempting to discover a block-structured process model directly, higher-quality process models can be obtained by discovering abstracted representation of an UBP, then transforming it to a structured one in a best-effort manner. This approach aims at discovering a SBP by operating into the following structuring techniques: 1- gateways structuring (repair unstructured gateways' representation), 2- clones' removal (remove from the process model repeated activities and by necessity actions) and 3- soundness repair (verify soundness of the obtained process model). The approach uses the BPMN as a process model representation language. It is adequately useful with our selected process discovery algorithm (heuristics miner), in terms of simplification. In our work, we use the [31] approach as the structuring operation that we will apply on the simplified BP version.

\subsection{Synthesis}

In this section, we have presented recent approaches of predicting, simplifying, structuring and auditing UBP. This is in the context of operational support systems and process mining techniques. First, we have decided which dimension will be used with the predictive process monitoring approach. This approach focused on predicting the remaining time dimension as numerical dimension. Second, we have defined the audit approach objective. This method combined the initial normative model with the frequent paths concept for auditing historic events, discovering and enhancing models. Third, we have selected the algorithm for simplifying real time event logs, which is heuristics miner. Fourth, we have defined the structuring techniques that can be combined with the simplification algorithm, to obtain structured BPs. In the following sections, we will illustrate how all these elements perform well together in reaching our UBP operational support approach objective.

\section{Our UBP operational support approach}

In this section, we detail our UBP operational support approach in terms of work entities and architecture. In this 


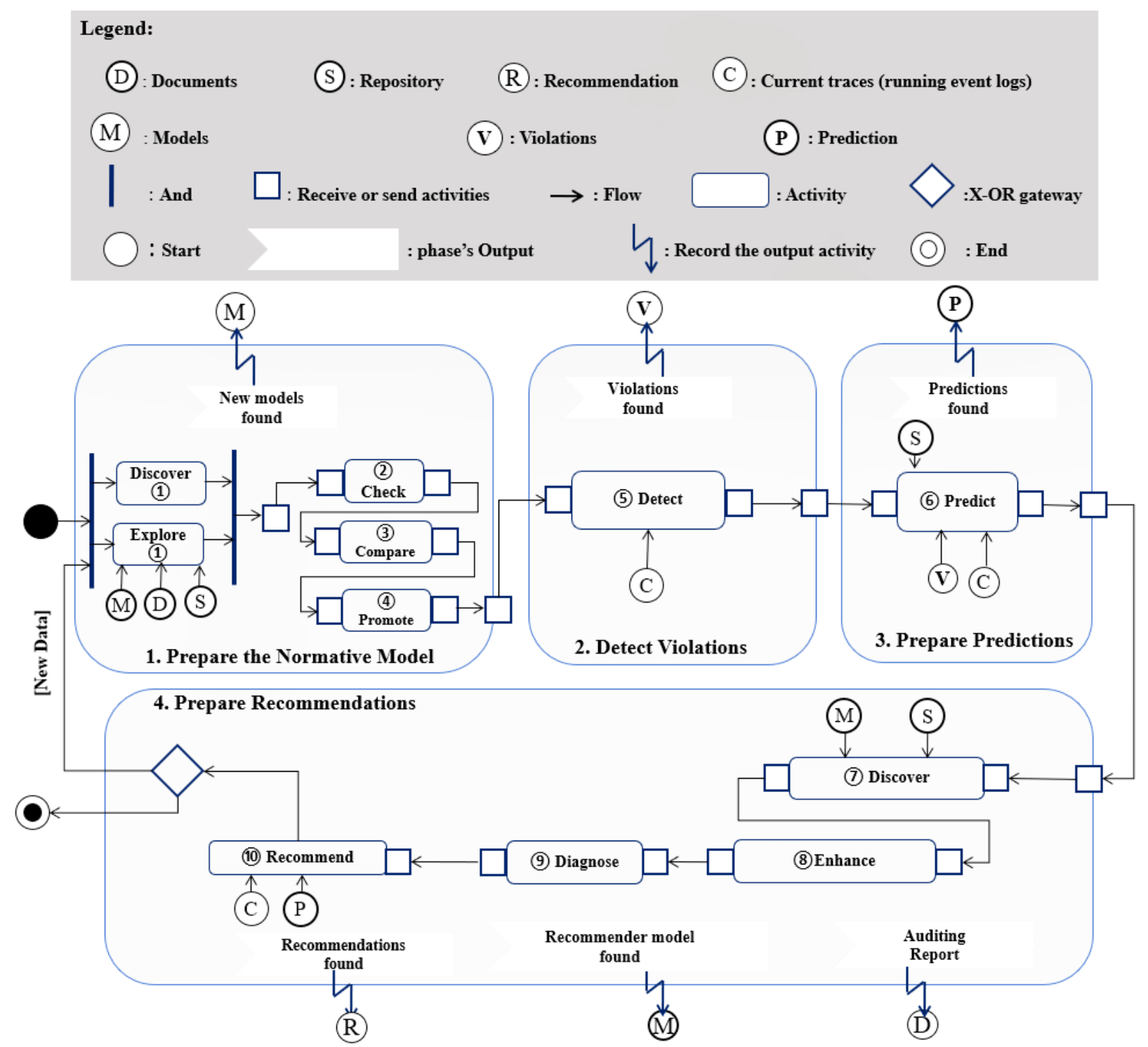

Figure 1. An overview of our approach

regard, we describe the process mining activities order (subsection 4.1) and we present their workflow through the enterprise work entities (sub-section 4.2).

\subsection{Our approach overview}

The complex structure of unstructured BPs requires the use of other process mining techniques. Therefore, we will re-use the refined process mining framework activities. The novelty, here, consists of re-ordering activities, to present a complete scenario of the existing techniques orchestration. In this respect, we arrange the process mining activities according to the following logic (Cf. Figure 1):

1. To achieve the UBP operational support objective, we require the existence of a SBP, an Initial Normative Model (INM) and a refined/final normative model.

2. To obtain the SBP of an UBP (de facto model), we apply the simplification algorithm combined with the [31] structuring techniques [31]. Here, we select heuristics miner algorithm for the Discover (1) activity.

In parallel, to define the initial normative model, we Explore (1) documentations and recorded models.

3. To obtain the refined normative model (Nominated as the de jure), it is required to use an audit approach by proceeding through these activities (Check (2), Compare (3) and Promote (4). At this stage, we use the SBP and the INM.

4. After obtaining the refined normative model and the SBP, we can detect violations (Detect (5)). This allows predicting events (Predict(6) using the predictive model. We can also Recommend (10) actions relatively to the obtained diagnosis information (discover (7), Enhance (8) and Diagnose (9) and the recommender model.

In our approach, we denote de facto model as an UBP be- 

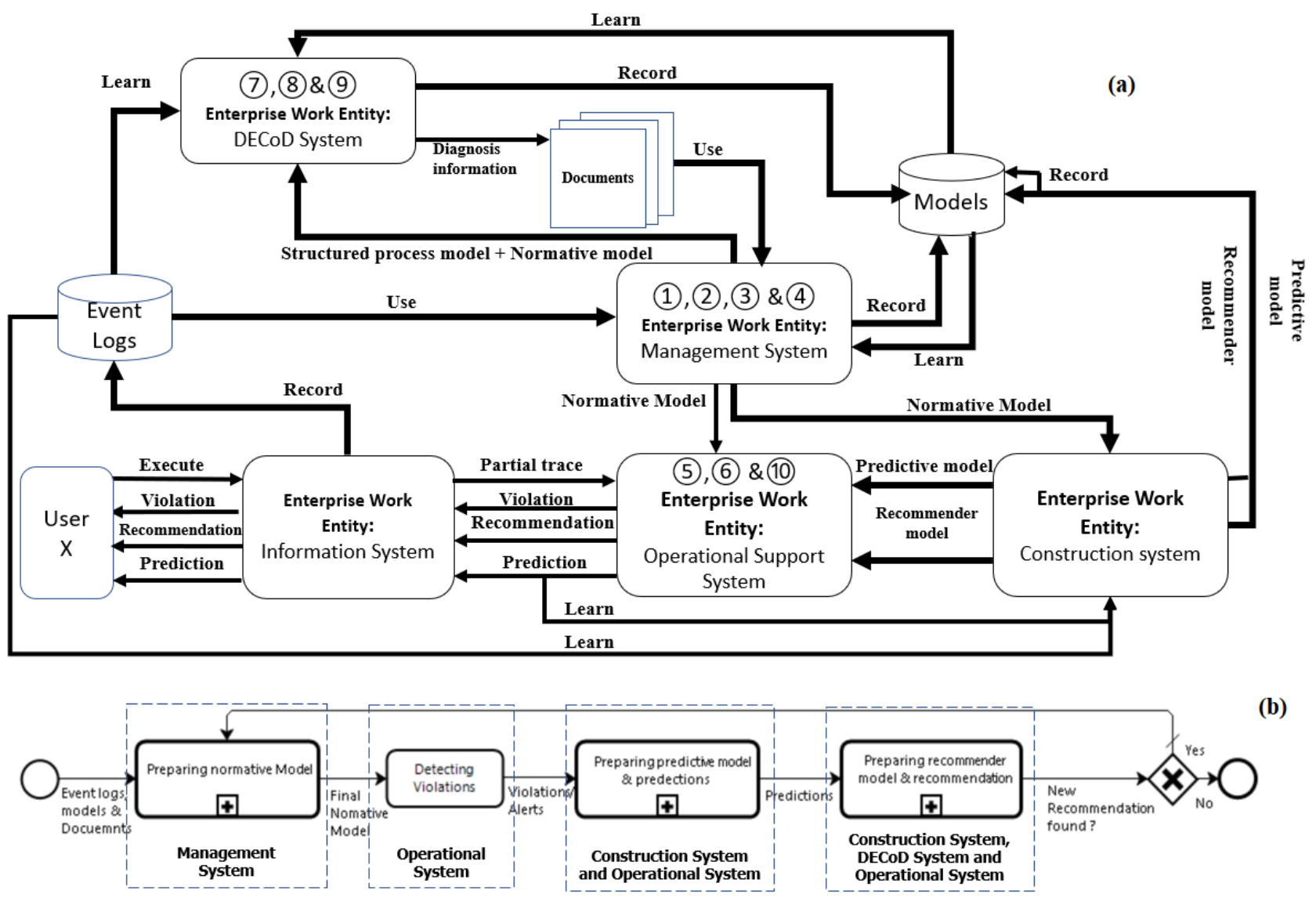

(b)

Figure 2. Our UBP approach architecture including work entities

Table 1. Enterprise work entities inputs and outputs

\begin{tabular}{|c|c|c|c|c|c|}
\hline $\begin{array}{l}\text { Work En- } \\
\text { tities }\end{array}$ & $\begin{array}{l}\text { management } \\
\text { System }\end{array}$ & $\begin{array}{l}\text { Operational Support } \\
\text { system }\end{array}$ & DeCOD system & $\begin{array}{l}\text { Construction } \\
\text { system }\end{array}$ & Information system \\
\hline Input & $\begin{array}{l}\text { Event logs, models, } \\
\text { documents }\end{array}$ & $\begin{array}{l}\text { historic and current } \\
\text { traces, predictive and } \\
\text { recommender mod- } \\
\text { els }\end{array}$ & $\begin{array}{l}\text { documents, event } \\
\text { logs and models }\end{array}$ & historic event logs & $\begin{array}{l}\text { User execution, } \\
\text { event logs }\end{array}$ \\
\hline Output & $\begin{array}{l}\text { Refined/Final nor- } \\
\text { mative model }\end{array}$ & $\begin{array}{l}\text { Violations, predic- } \\
\text { tions, recommenda- } \\
\text { tions }\end{array}$ & $\begin{array}{l}\text { Diagnosis infor- } \\
\text { mation }\end{array}$ & $\begin{array}{l}\text { Predictive model, } \\
\text { Recommender } \\
\text { model }\end{array}$ & $\begin{array}{l}\text { Informative mes- } \\
\text { sage, Alert }\end{array}$ \\
\hline
\end{tabular}

fore applying structuring techniques and as a SBP after the structuring step. As well as we denote a refined normative model as a de jure model or a final model. In this regard, we can present our approach into the following four phases (Cf. Figure 1):

We start by the phase of preparing the normative model using five activities: Discover, Explore, Check, Compare and Promote. This phase's output is a refined normative model. Then, we proceed to the second phase that aims at detecting violations using the Detect activity. According to the revealed violation and historic data, we can predict events in the third phase. Last, we use diagnosis information, to generate a recommender model and acquiring suitable recommendation using the Discover, the Enhance, the Diagnosis and the Recommend activities. All these operations will be explained and detailed in the following sections.

\subsection{Work entities and architectures}

In the company environment, we determine different enterprise work entities (part a in figure 2); each one releases a specific business. In the literature $[32,33]$, we distinguish:

1. The operational support system: allows supporting processes at runtime, in terms of detecting violations, predicting events and recommending actions by using normative/De jure, predictive and recommender models. 
2. The management system: allows defining normative models and business rules.

3. The information system: allows executing BP, recording events and communicating messages between users and other entities.

Additionally, our approach defines two new entities, which are the DECoD and the construction systems:

1. The DECoD (Discover Enhancement Conformance Diagnosis) system: allows generating diagnosis information required in the definition of predictions and recommendations.

2. The construction system: allows producing predictive and recommender models from historic event logs. These historic events are considered as a set of training data that aims at enriching predictive models.

To do so, the flow passes between and throughout these five entities performs as follows (part $b$ in figure 2): At the beginning, we prepare a refined normative model (Promoted version of de jure model). Then, we use it to detect current traces violations, i.e. processes that deviate from business rules. Next, we prepare a predictive model and by necessity we predict events according to detected violations, historic traces and current events. Consequently, we can construct the recommender model and recommendations. At the end, we record this latter and its corresponding violation alert. This operation is often attributed to the information system, i.e. it records predictions, models and auditing reports. This later broadcasts informative messages.

According to different phases' outputs, we propose to match each phase to a specific work entity (Approach phase $\rightarrow$ Enterprise work entity), which are: Preparing normative model (sub-subsection 4.2.1) $\rightarrow$ Management System; Detecting violations (sub-subsection 4.2.2) $\rightarrow$ Operational support system; Preparing the predictive model and predictions (subsubsection 4.2.3) $\rightarrow$ Construction system and Operational support system; Preparing the recommender model and recommendations (sub-subsection 4.2.4) $\rightarrow$ Construction system, DECoD system and the Operational support system.

In this sense, table 1 illustrates inputs and outputs data of each work entity. For instance, the management work entity uses documents, logs and models for producing a refined normative model.

In this order, we will explain each phase, the corresponding enterprise work entities and the process mining activities.

\subsubsection{Preparing the normative model}

The management work entity's output is a refined normative model (Cf. Figure 2) that allows auditing all executed behaviours. This model is obtained by applying the following steps:

1. We use data sources related to the analysed UBP for obtaining the Initial Normative Model (INM). In this sense, we apply the Explore activity. Meanwhile, we discover the UBP (de facto) using a simplification algorithm. Here, data sources are expressed as system documentation, user manuals, interviews report, etc. A concrete example is illustrated in sub-section 5.1.

2. We structure the discovered process model using structuring techniques.

3. We apply the Check activity to determine deviations between the INM and historic event logs. On board, we use SBP historic events, to investigate deviations causes. An applicable example is presented in sub-section 5.2.

4. We compare the SBP with the INM, in order to determine from where deviations come and what was expected instead. An example is demonstrated in subsection 5.3.

5. We promote the INM by the SBP in an auditing operation. This is released by filtering the SBP with the INM, to illustrate direct frequent paths that will encompass the refined normative model representation. In this regard, we detail a real life example in sub-section 5.4.

\subsubsection{Detect violations}

We can detect violations after obtaining the refined normative model. This is done by replaying current partial traces on the refined normative model (De jure). In this regard, we compares the de jure model to the current "pre mortem" data (events of running process instances) with the goal of revealing deviations at runtime. In case of violation, an alert is generated and recorded. The resulted data will be used in preparing the predictive model.

\subsubsection{Preparing the predictive model and predict events}

The existence of a predictive model is required to provide predictions. The predictive model is generated, from the construction system, based on the historic training data. This model learns by replaying many cases that can illustrate future expected events related to the studied context. According to the provided model, different predictions can be made. This is done by replaying current traces on the refined normative model, to explore possible predictions. In background, predictions are received by the information system, delivered to the final user and recorded as event logs (Cf. Figure 2).

\subsubsection{Preparing the recommender model and recommend- ing actions}

After saving predictions, we proceed to the DECoD system (Cf. Figure 2 and). This entity generates diagnosis information, which are based on the Discover (Applied on the historic data that include predictions), the Enhance (improves de facto model with historic events "predictions and recommendations") and the Diagnose (analyses de facto model for obtaining model performances) activities. Further, the DECoD system aims at verifying the similarity between de facto and the refined normative models (after each prediction or recommendation).

According to the diagnosis information, we can generate the recommender model. This model determines possible actions from which we can recommend one decision. To do so, we 
replay current traces on the recommender model. Behind, the suitable recommendation is received by the information system, broadcasted to the final user and recorded in the event logs repository (Cf. Figure 2).

\subsubsection{Synthesis}

In this section, we have proposed an UBP operational support approach. To this end, we used the refined process mining framework activities. Each activity can be related to a specific work entity. The correspondence between process mining activities and work entities is denoted as follows (System $\rightarrow$ Activities):

1. The management system $\rightarrow$ Discovery, Check, Compare and Promote.

2. The operational support system $\rightarrow$ Detect, Predict and Recommend

3. The DECoD system $\rightarrow$ Discover, Enhance, Diagnosis

4. The construction system $\rightarrow$ Produce the predictive and recommender models.

We observed that each work entity outputted a specific model or data forms. For instance, after applying the Enhance activity, we obtained an enhanced process model and after applying the Predict activity, we obtained events as predictions. Therefore, the diversity of these outputs and inputs present more challenging tasks in terms of communicating results and delivering decisions.

From a technical perspective, we suggest the use of these two research works [34] and [35] respectively published between 2016 and 2018. They propose different methods, to consolidate discovered process models. This is done by revealing conditional infrequent behaviours from event logs and examining multi-perspectives using alignment techniques.

\section{Illustrative example}

In this section, we present an illustrative example for simulating our UBP operational support approach. The example is about the road ${ }^{2}$ traffic fine management process. The controlflow process model consists of 11 activities and 561470 events grouped into 150370 cases. By definition, this process model is considered as an UBP (Cf. Figure 3).

Throughout this section, we apply the four phases of our UBP operational support approach (Cf. Figure 1), in order to treat a real-life UBP example. To do so, we demonstrate how workflows are passed between and through our UBP operational support approach work entities, respectively to the following order: (sub-section 5.1) preparing normative model in the management entity, (sub-section 5.2) detecting violations in the operational support entity, predicting and recommending events at runtime into construction and operational support entities (sub-sections 5.3 and 5.4).

\footnotetext{
${ }^{2}$ https://data.4tu.nl/repository/uuid:270fd440-1057-4fb9-89a9b699b47990f5
}

\subsection{Preparing the normative model}

This sub-section applies the first phase of our UBP operational support approach. It aims at preparing the refined normative model. This model allows detecting deviations according to specifics business boundaries. It also nominated as the final normative model. For this purpose, it is important to use simplification algorithms, structuring, checking, comparing and promoting techniques.

\subsubsection{Simplification and structuring}

Our process, with excerpt illustrated in figure 3, starts with a fine being created (i.e., Create Fine). After, a fine has been created, it is sent to the offender's place of residence (i.e., Send Fine). When the offender receives the fine, the date of reception of such notification is also registered (i.e., Insert Fine Notification). After this action, the fine should be paid within 60 days (i.e., Payment). However, in case the fine was physically handed over to the offender, e.g. by means of a parking ticket, the offender is able to immediately pay the fine. In such case, the fine will not be sent and there will be no registration of the notification. This exception, i.e., direct payment after ticket creation saves the offender administration costs. In total, the offender has 60 days to either pay the fine or appeal against it. After this period, a penalty is added to the fine amount (i.e., Add Penalty).

For reducing the process complexity (transform UBP to SBP), we suggest to use these two approaches $[34,36]$. The first approach aims at simplifying an UBP using the heuristics miner algorithm. The second approach aims at structuring a simplified model by removing incoherent elements. Thus, we obtain a structured process.

After obtaining the SBP, we look for its related refined normative model. This helps in analysing the SBP as an auditing action. In this regard, we promote the INM with the SBP to obtain the final normative.

All in all, we propose a framework for structuring the UBP and refining the normative model.

Our framework starts by the extraction of UBP event logs and their simplification, using heuristics mining technique [25]. This algorithm abstracts a process model based on the frequency activity parameter, which can extract main behaviours of an unstructured process (here, it produces a de facto model). The current step is repeated until obtaining a concrete simplified BP with fitness value at least equal to 0.8 (i.e. at least $80 \%$ of behaviours should match between model and the event $\log$ ).

After obtaining the simplified process model, we apply the structuring techniques for generating a SBP (latest or improved version of de facto model). Then, we proceed to the audit phase, which includes the Check, the Compare, and the Promote activities. Here, we obtain a refined normative model, which aims at filtering the SBP with an INM (INM is often nominated as de jure model), in order to extract the control-flow related features. These features serve mainly to identify frequent execution paths with an abstracted representation (Cf. Figure 4). 


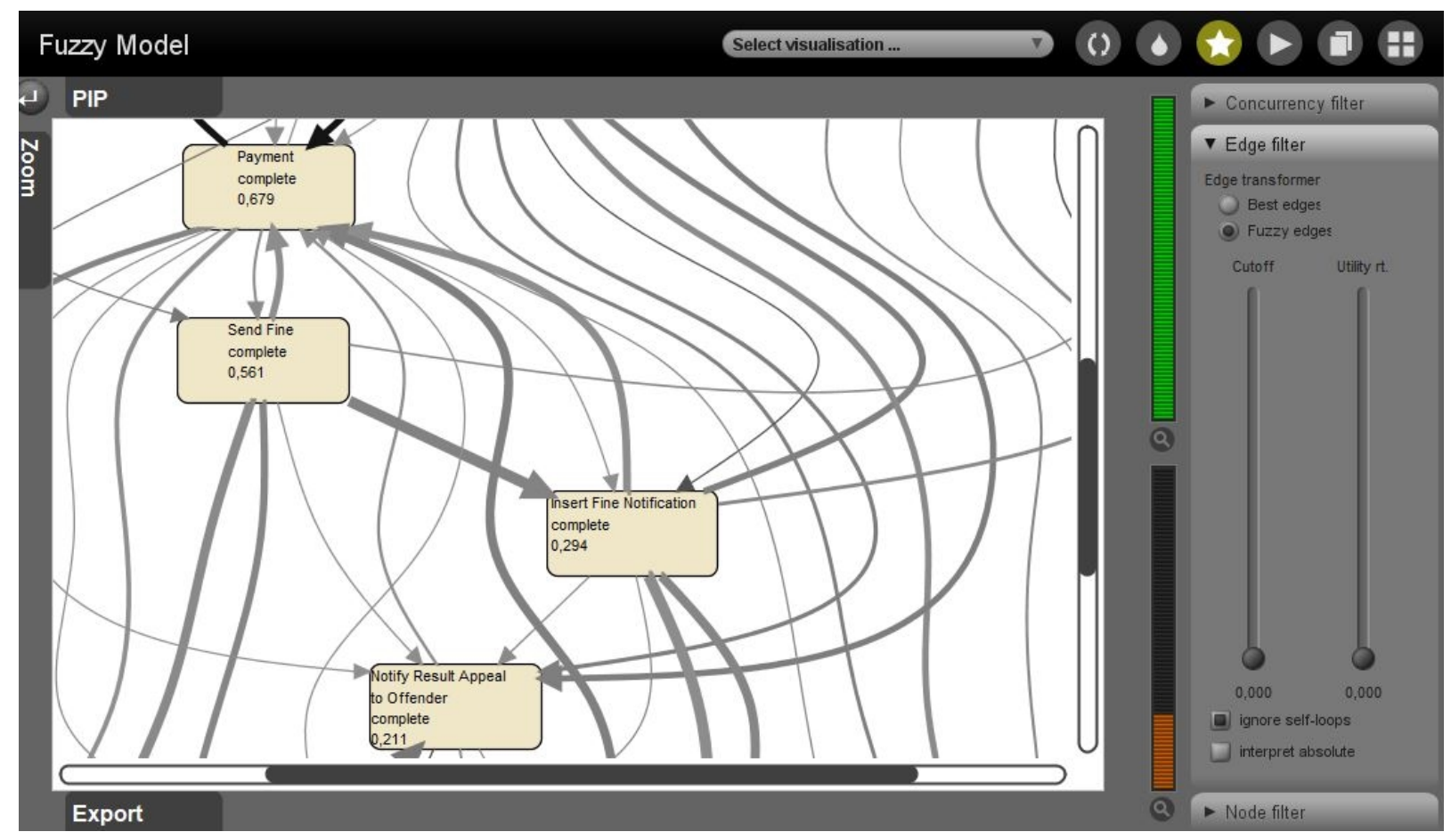

Figure 3. An unstructured process: Excerpt showing $20 \%$ of road traffic fine management process

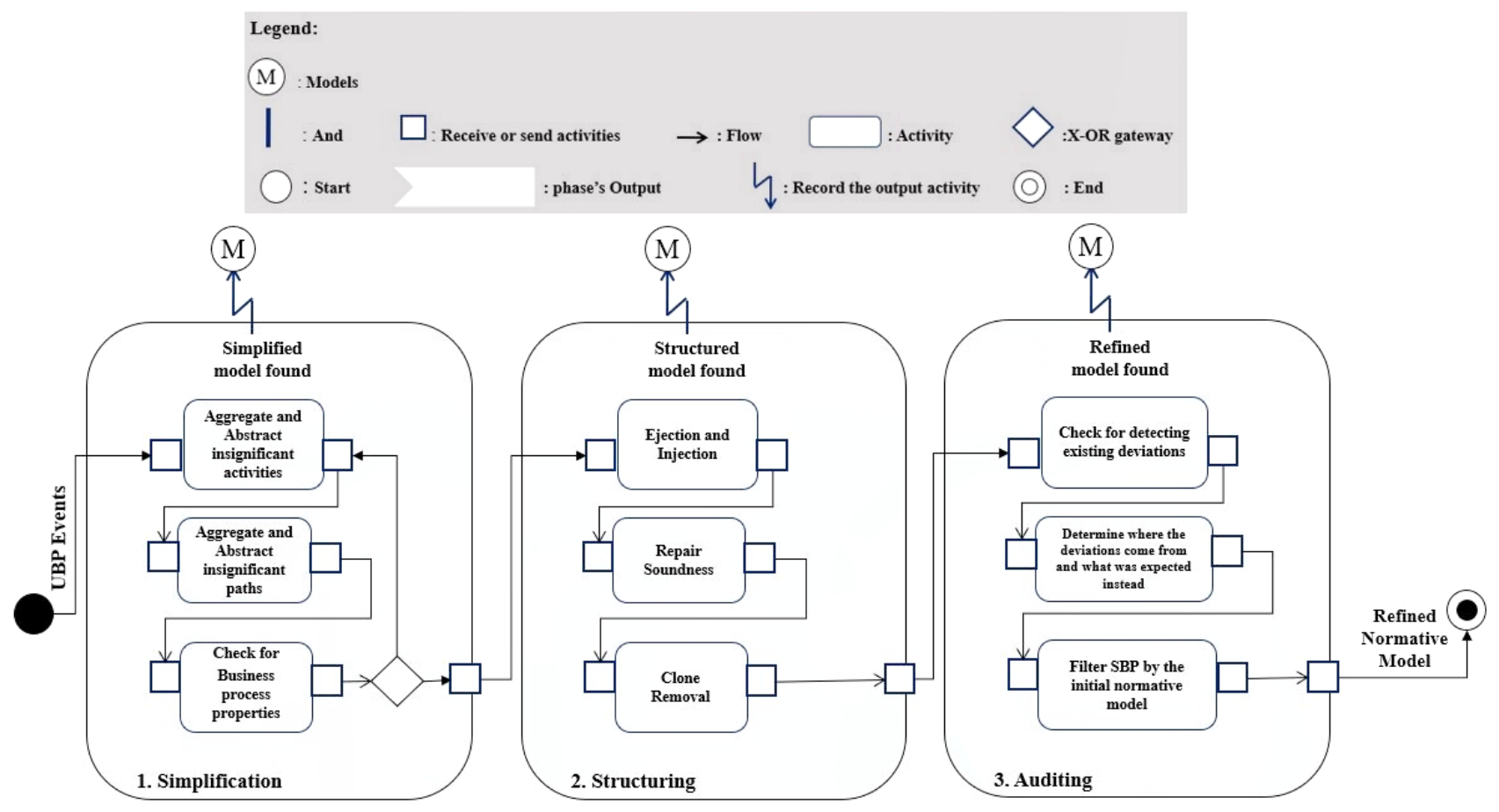

Figure 4. Framework for producing structured and refined normative models

In this example, we consider works treating the process at hand, as data sources of the INM. For instance, we use these two works $[34,36]$ for obtaining the control-flow INM. In our example, we apply the simplification phase using the heuristics miner algorithm (Cf. Figure 5). This aims at discov- ering the de facto process model that can be converted to other modelling languages like: BPMN [37, 38, 39], in order to use structuring techniques (gateways structuring, soundness repair, clone removal) as the second phase of our framework. In figure 6, we observe that the converted model does not 


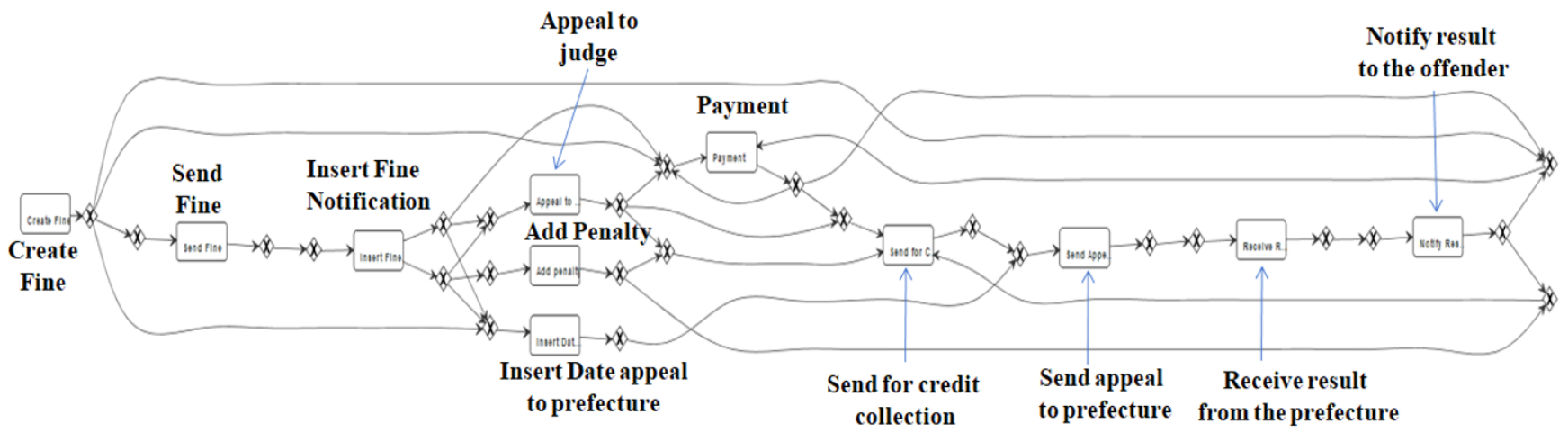

Figure 5. Simplified process model discovered using heuristics miner algorithm

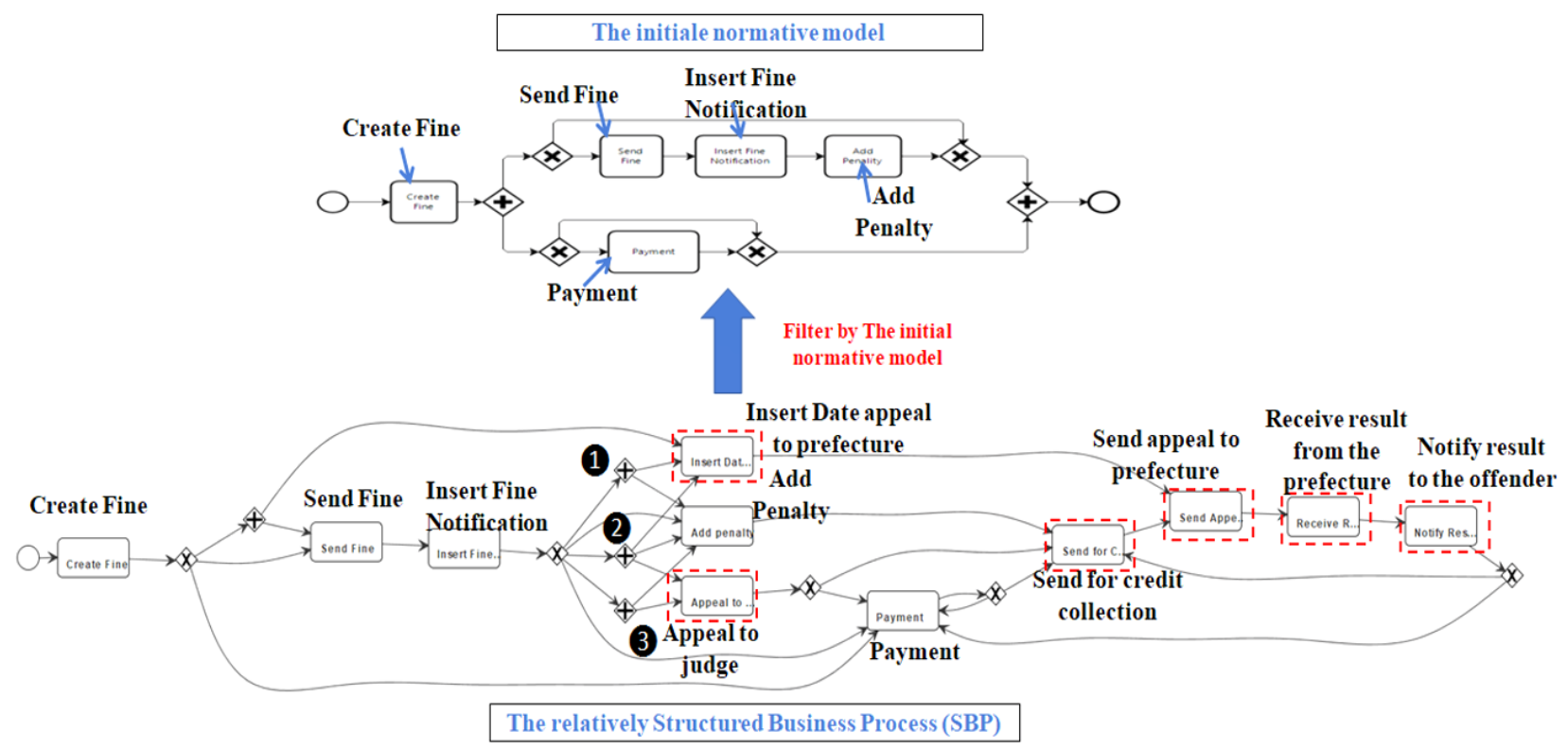

Figure 6. Filtering the SBP by the initial normative model (Promote)

respect the [31] structuring techniques. For instance, XOR gateways are unstructured. Therefore, we must use structuring techniques.

The structuring techniques application results the process model illustrated in figure 7 . This model is relatively structured; we can use it to reach specifically the next step of our simplification framework (Cf. Figure 4), i.e. the auditing step and generally next phases of our UBP operational support approach (Cf. Figure 1), i.e. detect violations.

For further process model structuration, we suggest the adjustment of the three parts $(\mathbf{0}, \mathbf{2}$ and $\mathbf{3})$ of the figure 7.

\subsubsection{Auditing}

At the beginning of this phase, we check where and why the INM deviates from historic events. Then, we compare the INM to the de facto model (SBP), in order to analyse these deviations. Consequently, we observe the appearance of new activities. This is representing deviations causes between the INM and de facto model (Cf. Figure 6): 1-Insert date appeal to prefecture, 2-Send for credit, 3-Send appeal to prefecture, 4Receive result from prefecture, 5-Notify result to the offender and 6-Appeal to judge. Last, the INM will be promoted based on the SBP model, in order to obtain the refined normative model.

The frequency matrix (shows percentage of the direct flows between activities) is absolutely integrated into the heuristics miner algorithm application. Moreover, deviations emerged between the INM and the SBP are detected with the comparing and the checking activities. Therefore, we proceed directly to the refine action by filtering the SBP with the INM into the Promote activity. This is producing a new frequency matrix that can generate a refined normative model (Cf. Figure 8$)$. In this sense, we use two values $(1,0)$ for defining relations between the finding activities (solid or not exist). The activities illustrated in table 2 are resulted after applying the filtering step (Promote accoridng observed deviations), i.e. 

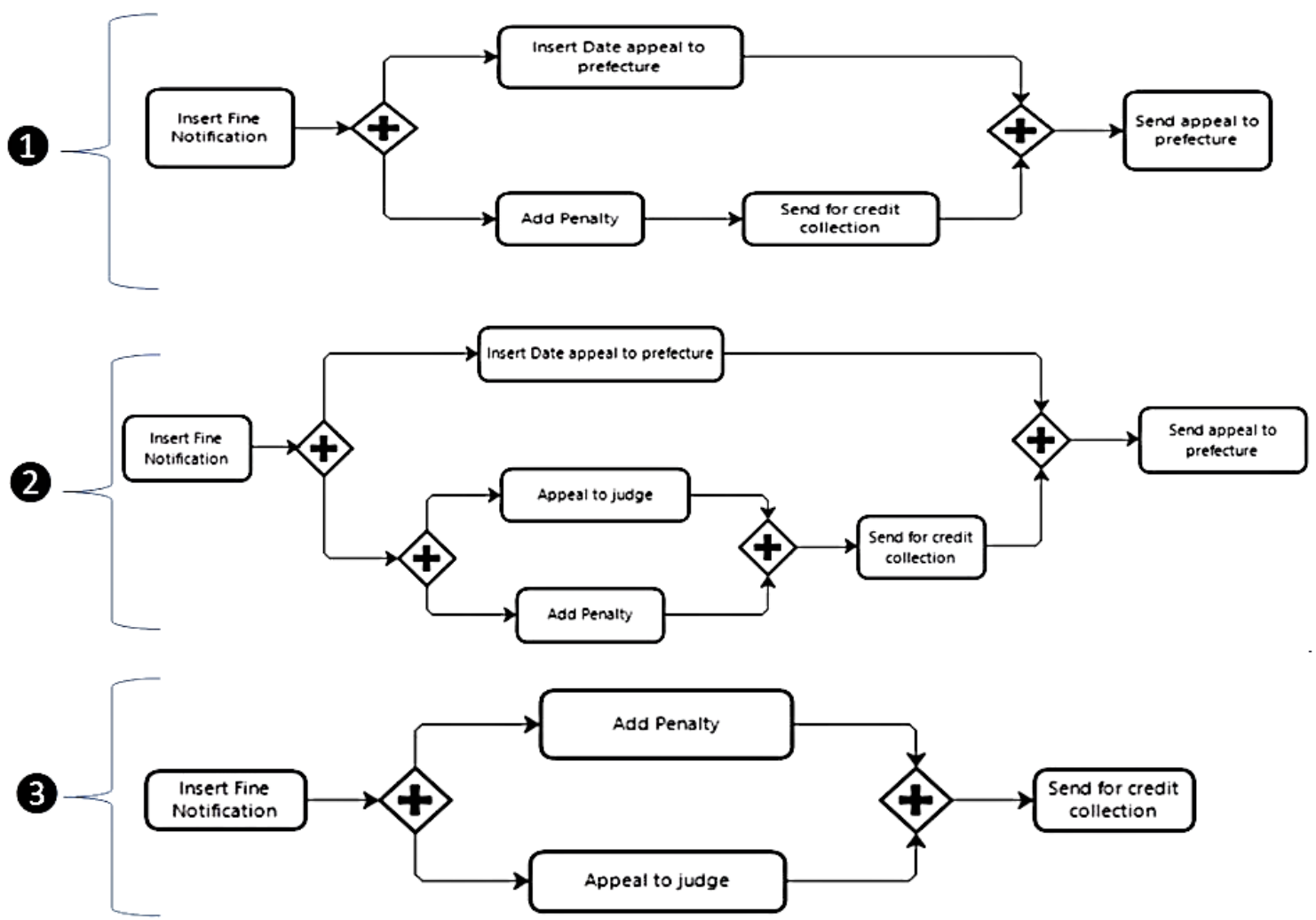

Figure 7. Re-structuring the de facto process model parts $\mathbf{0}, \mathbf{2}$ and $\mathbf{3}$

the entire $\log$ activity named $\mathrm{CF}^{3}$ has a solid relation with the $\mathrm{SF}^{4}$ activity. For instance, $\mathrm{CF}$ as $\mathrm{x}$ is directly followed by SF as $\mathrm{y}(\mathrm{x}>\mathrm{y})$.

According to table 2, new activities are observed and must be handled by the refined normative model (Cf. Figure 8), which are: CF (Create Fine), SF (Send Fine), I (Insert Fine Notification), A (Add penalty), P (Payment), SP (Send appeal to Prefecture), ID (Insert Date appeal to prefecture), RP (Receive result from the Prefecture), NO (Notify result to the Offender), AJ (Appeal to Judge), SC (Send for credit Collection). Therefore, the new process is described as follows: If the offender appealed against the fine within 60 days, the appeal is sent to the corresponding prefecture (Send Appeal to Prefecture), which is registered when it is received (Insert Date Appeal to Prefecture). The results of the appeal are sent back to the municipality (Receive Result Appeal from Prefecture) and they are notified to the offender (Notify Result Appeal to Offender), which can appeal against the result (Appeal to Judge). If the offender does not pay (possibly after a denied appeal), the fine is sent for credit collection (Send for Credit Collection).

The refined normative model is represented within Petri Net notation. This notation is suitable to next verifications. The model, illustrated in figure 8 , does not capture any form of parallelism. It is merely a sequence of activities combined

\footnotetext{
${ }^{3}$ Create Fine

${ }^{4}$ Send Fine
}

with possible choices.

To conclude, The input data (event log) was organized to promote the discovery task by clustering the log into deviated and none-deviated activities, to obtain different sub-logs. These sub-logs are used to carry out the activities presented in the workflow.

Therefore, the efficiency of the transformation, UBP to SBP, is demonstrated in the simplicity and the structuring of the resulted road traffic process. As appeared in figure 3, the control-flow was with a complex structure. After the transformation, it appears in a readable form with reduced number of activities and paths (Cf. Figure 8).

\subsection{Detect}

In this step, we apply the second phase of our UBP operational support approach. We try to detect violations at runtime. Indeed, we replay this trace** $<C F_{\text {start (10) }}, C F_{\text {complete }(20)}$, $S F_{\text {start (25) }}, S F_{\text {complete (30) }}, I_{\text {start (31) }}, A_{\text {start (32) }}>$ on the refined normative model.

At time 10, after executing the first event $C F_{\text {start }(10)}$ no deviation is found because trace the $C F_{\text {start }(10)}$ can be replayed without missing tokens. The next two events can also be replayed, i.e., $C F 10_{\text {start }}$, $C F 20_{\text {complete }} S F 25_{\text {start }}$ is a possible firing sequence of the Work Flow net, in which each activity is refined into a start and complete transition. The next event, i.e., $A_{\text {start (32) }}$ is not possible in this state. Hence, an alert is generated at time 28 . The alert signals that activity 
Table 2. frequency matrix for applying the Promote activity (x followed by y)

\begin{tabular}{llllllllllll}
\hline $\mathrm{x}>\mathrm{y}$ & $\mathrm{CF}$ & $\mathrm{SF}$ & $\mathrm{I}$ & $\mathrm{A}$ & $\mathrm{P}$ & $\mathrm{SP}$ & $\mathrm{ID}$ & $\mathrm{RP}$ & $\mathrm{NO}$ & $\mathrm{AJ}$ & $\mathrm{SC}$ \\
\hline $\mathrm{CF}$ & 0 & 1 & 0 & 0 & 1 & 0 & 0 & 0 & 0 & 0 & 0 \\
\hline $\mathrm{SF}$ & 0 & 0 & 1 & 0 & 0 & 0 & 0 & 0 & 0 & 0 & 0 \\
\hline $\mathrm{I}$ & 0 & 0 & 0 & 1 & 1 & 1 & 0 & 0 & 0 & 0 & 0 \\
\hline $\mathrm{A}$ & 0 & 0 & 0 & 0 & 1 & 0 & 0 & 0 & 0 & 0 & 1 \\
\hline $\mathrm{P}$ & 0 & 0 & 0 & 0 & 0 & 0 & 0 & 0 & 0 & 0 & 0 \\
\hline $\mathrm{SP}$ & 0 & 0 & 0 & 0 & 0 & 0 & 1 & 0 & 0 & 0 & 0 \\
\hline $\mathrm{ID}$ & 0 & 0 & 0 & 0 & 0 & 0 & 0 & 1 & 0 & 0 & 0 \\
\hline $\mathrm{RP}$ & 0 & 0 & 0 & 0 & 0 & 0 & 0 & 0 & 1 & 0 & 0 \\
\hline $\mathrm{NO}$ & 0 & 0 & 0 & 0 & 0 & 0 & 0 & 0 & 0 & 1 & 0 \\
\hline AJ & 0 & 0 & 0 & 0 & 1 & 0 & 0 & 0 & 0 & 0 & 1 \\
\hline $\mathrm{SC}$ & 0 & 0 & 0 & 0 & 0 & 0 & 0 & 0 & 0 & 0 & 0 \\
\hline
\end{tabular}

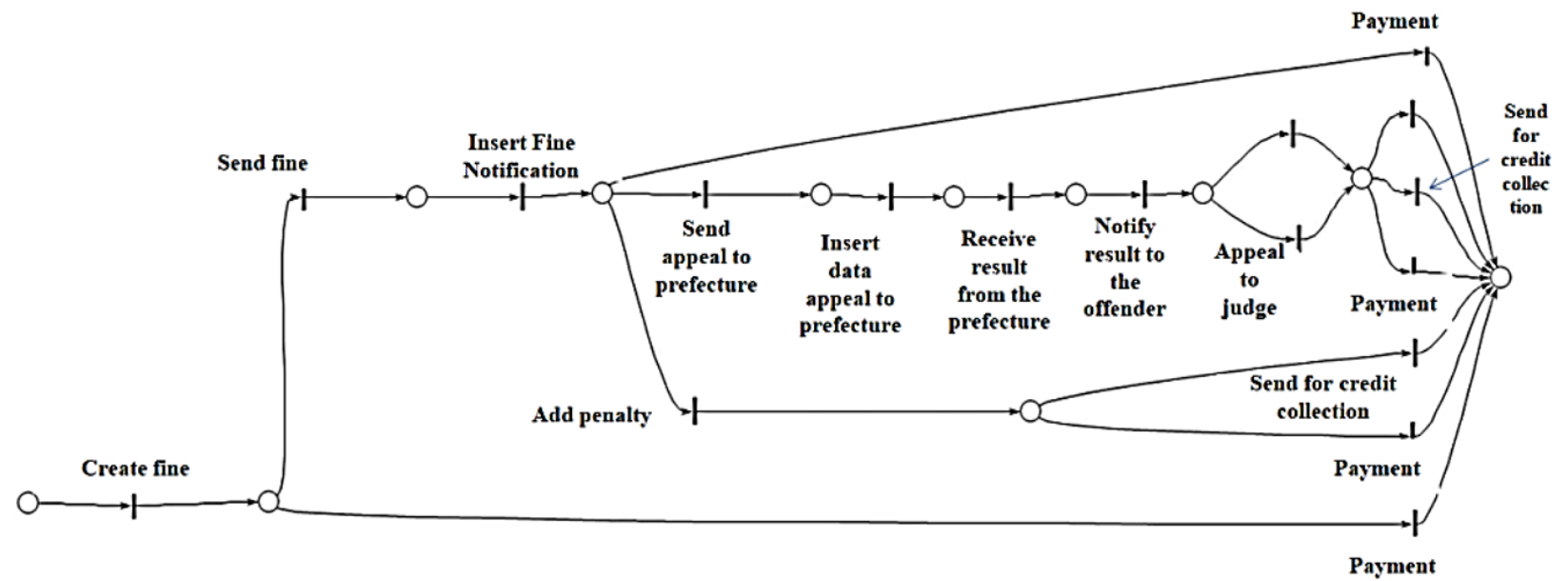

Figure 8. The refined normative model with Petri Net notation (Excerpt)

A was started without being enabled. Therefore, a violation, in the activity Add Penalty, is detected because it is started while the insert fine notification is not released yet: $<$ $C F_{\text {start (10) }}, C F_{\text {complete (20) }}, S F_{\text {start (25) }}, S F_{\text {complete(30) }}, I_{\text {start (31) }}$, $A_{\text {start (32) }}>$.

Therefore, it is important to predict when the insert fine notification activity should be achieved to start the A activity. This puts forward the need of a predictive model.

\subsection{Preparing the predictive model and predictions}

In this sub-section, we apply the third phase of our UBP operational support approach (Cf. Figure 2). We aim to prepare the predictive model and predictions. In this context, the predictive model learns from historic events, in order to collect possible predictions. To do so, we use an example of historic traces, mentioned in table 3, for constructing the predictive model. In this sense, it is possible to make predictions about future events, e.g., the remaining flow time and the probability of success. This is done by combining information about running cases with discovered models as SBP or hand-made as de jure model. For example, we use the following parameters, to predict the completion time of the insert fine notification activity: the remaining flow time of the targeted case, the
Table 3. Historic traces

\begin{tabular}{|c|c|c|}
\hline CaseID & Trace & \\
\hline 1 & $\begin{array}{l}C F_{\text {start }(12)}, \quad C F_{\text {complete }(19)}, \\
S F_{\text {complete }(35)}, \quad I_{\text {start }(36)}, \\
A_{\text {start }(45),}, A_{\text {complete }(50)}, \\
P_{\text {complete }(70)}\end{array}$ & $\begin{array}{r}S F_{\text {start }(25)}, \\
I_{\text {complete }(40)}, \\
P_{\text {start }(61)},\end{array}$ \\
\hline 2 & $\begin{array}{l}C F_{\text {start }(25)}, \quad C F_{\text {complete }(30)}, \\
S F_{\text {complete }(26)}, \quad I_{\text {start }(27)}, \\
A_{\text {start }(35)}, A_{\text {complete }(40)}, \\
P_{\text {complete }(46)}\end{array}$ & $\begin{array}{r}S F_{\text {start }(32)}, \\
I_{\text {complete (33) }}, \\
P_{\text {start (41) }},\end{array}$ \\
\hline 3 & $\begin{array}{l}C F_{\text {start }(17)}, \quad C F_{\text {complete }(23)}, \\
S F_{\text {complete }(32)}, \quad I_{\text {start }(33)}, \\
A_{\text {start }(50)}, A_{\text {complete }(59)}, \\
P_{\text {complete }(75)}\end{array}$ & $\begin{array}{r}S F_{\text {start }(28)}, \\
I_{\text {complete (38) }}, \\
P_{\text {start (70) }},\end{array}$ \\
\hline & & \\
\hline
\end{tabular}

sojourn time (Time spent in a state before passing to the next) of each case and the elapsed time at a specific state. To this end, figure 9 demonstrates the replaying operation of three cases. In this figure, the initial state [start] has no annotations since no events have occurred when visiting this state. The final state [P4] has no sojourn time because there is no next 


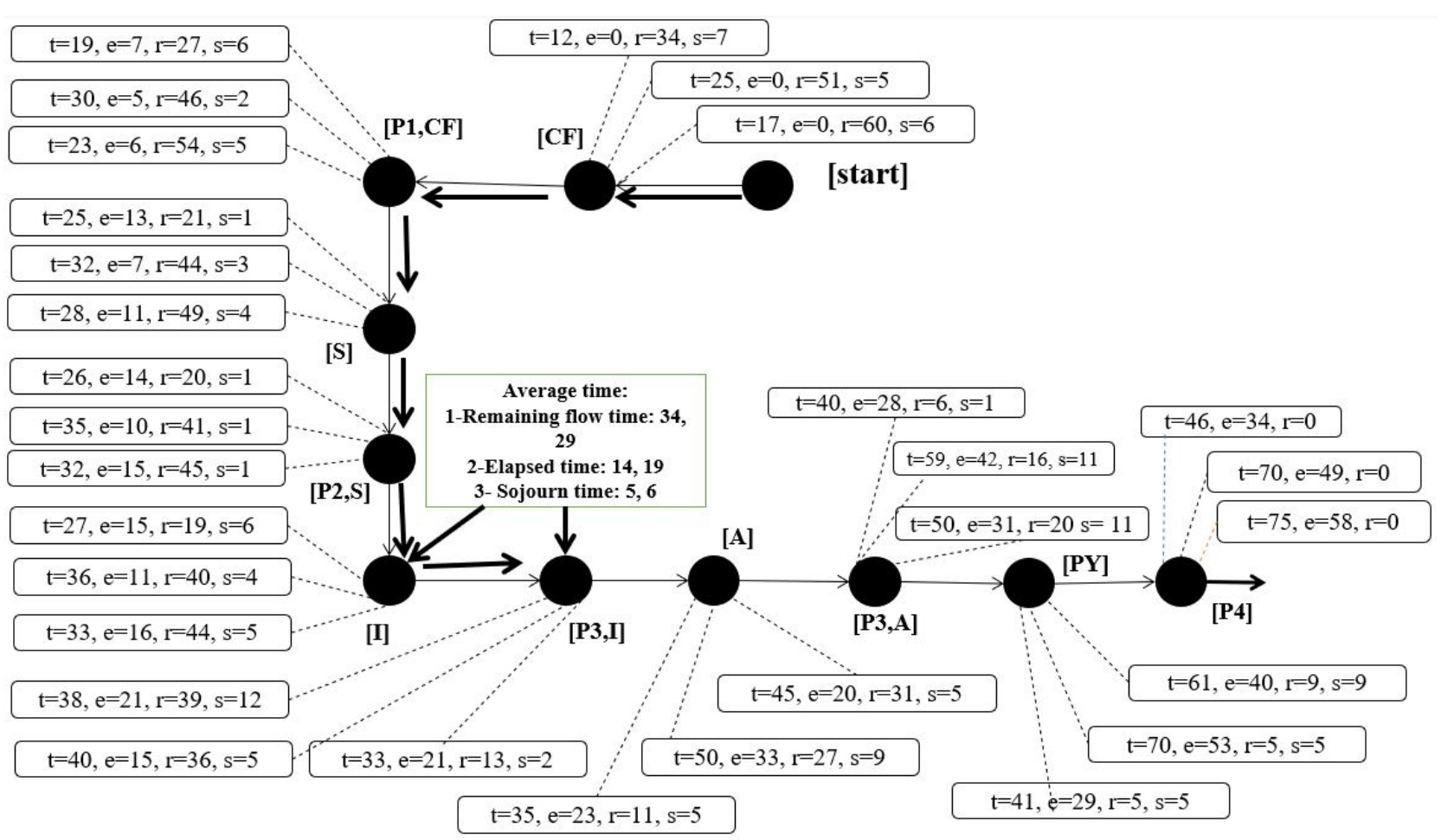

Figure 9. Statistics while replaying the historic cases ( $\mathrm{t}$ : the time the state is visited, e: the elapsed time from the start when visiting the state, $\mathrm{r}$ : the remaining flow time, $\mathrm{s}$ : the sojourn time)

event, when visiting this state. Let us consider the first case $<C F_{\text {start (12) }}, C F_{\text {complete(19) }}, S F_{\text {start (25) }}$, SF complete(26),$I_{\text {start (27) }}$, $I_{\text {complete(33) }}, A_{\text {start (35) }}, A_{\text {complete(40) }}, P_{\text {start(41) }}, P_{\text {complete(46) }}>$. This case started at time 12 and ended at time 46. Hence, its flow time was 34 time units. States visited by this case are annotated with a tag $(\mathrm{t}, \mathrm{e}, \mathrm{r}$ and $\mathrm{s})$ where $\mathrm{t}$ is the time of the state is visited, $\mathrm{e}$ is the elapsed time since the start when visiting the state, $\mathrm{r}$ is the remaining flow time, and $\mathrm{s}$ is the sojourn time. State $[\mathrm{CF}]$ is tagged with the annotation $(\mathrm{t}=12$, $\mathrm{e}=0, \mathrm{r}=34, \mathrm{~s}=7$ ) because this state was visited by the case directly after the first event ${ }_{\text {CF Start } 12}$ occurred. $\mathrm{t}=12$ because event CF12 start occurred at time 12. $\mathrm{e}=12-12=0$ because no time elapsed after executing just one event. $r=46-12=34$ is the remaining time until the end of the case after $\mathrm{CF}$ was started at time 12. $\mathrm{s}=19-12=7$ because the next event occurred 7 time units later. State $[\mathrm{p} 1, \mathrm{CF}]$ is tagged with annotation $(\mathrm{t}=$ $19, \mathrm{e}=7, \mathrm{r}=27, \mathrm{~s}=6$ ) because CF completed at time $\mathrm{t}=19$. $\mathrm{e}=19-12=7$ because CF completed 7 time units after the case started. $r=46-19=27$ because the case ended at time 46. $s=25-19=6$ because the next event occurred 6 time units later.

At this stage, we use these methods [21, 28, 40], for predicting the remaining time of the ambiguous activity (insert fine notification activity). Due to the availability of data (road traffic fine event), tool (Prom plug-ins) and data context (Van Der Aalst et al., 2011; Polato et al., 2014), these two methods are considered as completed approaches that every researcher can rely on, to start developing new predictive techniques (related to the public administration domain) and to test impacts on other predictive business monitoring dimensions. For instance, we can demonstrate how the predicted remaining time can influence the next activity in terms of performance (Add penalty) and how this can lead us to select suitable resource to the insert fine notification.

After replaying historic events, we can now predict future ones. In our example, we conclude the following method for calculating the remaining flow time, the elapsed time and the sojourn time. The average remaining flow time is calculated by applying $\frac{R}{C}=\frac{\sum_{i=1}^{3} r_{i}}{\sum_{i=1}^{3} c_{i}}$, where $\mathrm{R}$ is the sum of all remaining time in the concerned state (in our case at the state I start(27), we aim to calculate the remaining time: $\left.\mathrm{R}=\sum_{i=1}^{3} r_{i}\right)$ and $\mathrm{C}$ is the number of cases replayed (In our example, we have three cases $\left.\sum_{i=1}^{3} c_{i}\right)$. The average sojourn time is obtained by applying $\left(\frac{S}{C}=\frac{\sum_{i=1}^{3} s_{i}}{\sum_{i=1}^{3} c_{i}}\right)$ where $\mathrm{S}$ is the value of sojourn time of each case at a specific state: $\mathrm{S}=\sum_{i} s_{i}$ ) and the average elapsed time $\left(\frac{E}{C}=\frac{\sum_{i=1}^{3} e_{i}}{\sum_{i=1}^{3} c_{i}}\right)$ where $\mathrm{E}$ is the value of elapsed time of each case at a specific state: $\mathrm{E}=\sum_{i=1}^{3} e_{i}$ ).

Therefore, predictions are: $\left\langle C_{F \text { start (10) }}, C F_{\text {complete (20) }}, S F_{\text {start (25) }}\right.$, $S F_{\text {complete(30) }}, I_{\text {start (31) }}, I_{\text {complete(36) }}, A_{\text {start(42) }}>. I_{\text {complete(36) }}$, 
denotes the time required, to achieve the insert fine notification activity. $A_{\text {start (42) }}$ denotes the time to start the add penalty activity. Last, we record all predictions.

In our example, we look for a sample application to prove our concept. Therefore, we use the simplification of an UBP to a SBP that makes the resolution time predictor seems too simple, instead of its complexity in real-life events. In this sense, we focus on three specific cases, to avoid application errors, while focusing on multiple dimensions can provide complex applications.

\subsection{Preparing the recommender model and recom- mendations}

In this sub-section, we apply the fourth phase of our UBP operational support approach (Cf. Figure 2). We aim to prepare the recommender model and recommendations. In this order, we use predictions report, to discover the latest version of the de facto model. Then, we treat its diagnosis information. This information aims at enhancing the de facto model and obtaining the recommender model, through the Discover, the Enhance and the Diagnosis activities.

\subsubsection{Diagnosis information}

Analysing the de facto model (SBP) can give general insights, of the whole process model performance, and specific ones of each activity's performance. In our example, we choose to diagnose information from the social network investigation. Appropriately, we present the road traffic fine management discovered process model according to the social network resources (Cf. Figure 10). Theoretically, each activity is attached to a specific cluster (resources executing the same activity). At this stage, we focus on the insert fine activity. We observe that cluster $\mathrm{C}$ resources are handling this activity. Based on the discovered social network information, we proceed to the Enhance activity application. In this sense, process model improvement can be performed from different process mining perspectives [41]. Among these perspectives, we find those dealing with control-flow perspective, organizational perspective, data-flow perspective, etc. To do so, the de facto model uses historic data, i.e. recorded predictions, for potential improvements. This is done by applying the conformance checking technique. Thus, if we observe that the de facto model deviates from the de jure model, we apply the Enhance activity.

According to table 4, we focus on the time perspective. In this sense, we observe delays in the insert fine notification activity. This activity must be achieved in 5 minutes but it is attained between 5 and 7 minutes. The boundary rule has been not respected. Based on the selected BP predictive method (sub-section 3.1), cluster $\mathrm{C}$ resources are responsible for these emerged delays. At this stage, we can enhance the de facto model according to detected deviations.

For advanced models investigation, we apply the Diagnosis activity on the de facto model and the predicting events. In our case example, the de facto model will be the same in terms of control-flow representation, because modifications are influencing only the timestamp proprieties of the Insert fine Notification activity and the add penalty activity.

In reality, a de facto model differs from a historic one because of major modifications that aims at improving this latter to a normative model. This progressive transformation complies with a set of predefined rules. Indeed, the de facto model, under ideal conditions, can be similar to the normative model.

Table 4. Performance of Cluster $\mathrm{C}$ resources

\begin{tabular}{llll}
\hline CaseID & Activity & $\begin{array}{l}\text { Timestamp of the } \\
\text { de facto model } \\
\text { (minutes) }\end{array}$ & $\begin{array}{l}\text { Timestamp of the } \\
\text { de Jure model } \\
\text { Rules (minutes) }\end{array}$ \\
\hline Trace1 & $\begin{array}{l}\text { Insert } \\
\text { Fine } \\
\text { notifi- } \\
\text { cation }\end{array}$ & $06: 00$ & $05: 00$ \\
\hline Trace2 & Idem & $07: 12$ & $05: 00$ \\
\hline Trace3 & Idem & $05: 00$ & $05: 00$ \\
\hline Trace4 & Idem & $05: 00$ & $05: 00$ \\
\hline Trace5 & Idem & $05: 35$ & $05: 00$ \\
\hline
\end{tabular}

\subsubsection{Prepare the recommender model}

After obtaining the diagnosis information, we can prepare the recommender model. Here, our objective is to find out the suitable resource to execute the insert fine notification activity, respectively to the predicted time (sojourn time: 5 units and completion time at 36). To do so, the existence of a recommender model is required. This model defines possible actions from which one decision can be chosen. This decision is learned from historic data (events represent predictions) and diagnosis information. In the present example, the recommender model should illustrate appropriate resources to the insert fine notification activity and sojourn time corresponding to each resource (Cf. Table 5). In this regard, we analyse clusters resources and their corresponding activities. Mainly, we focus on the cluster $\mathrm{C}$. This cluster is responsible for the execution of the insert fine notification activity (Cf. Figure 10). It contains 8 resources. We mentioned, in table 5, the recorded sojourn time of each resource in order to decide which one is the most responsive.

In reality, a resource cluster may execute attached activities to other clusters. For instance, cluster B resources can execute, in a specific time and in a specific situation, the payment activity which is attached to cluster E3 resources. In this context, more parameters can be used to obtain suitable and refined cluster classification.

\subsubsection{Recommend}

To provide a recommendation, we replay current partial traces on the recommender model. This allows defining possible actions from which we choose one. In our illustrative example, we recommend $\mathrm{R} 35$ as a suitable resource to execute the insert fine notification activity. This decision is based on calculating the activity executing certainty, taking into consideration the 


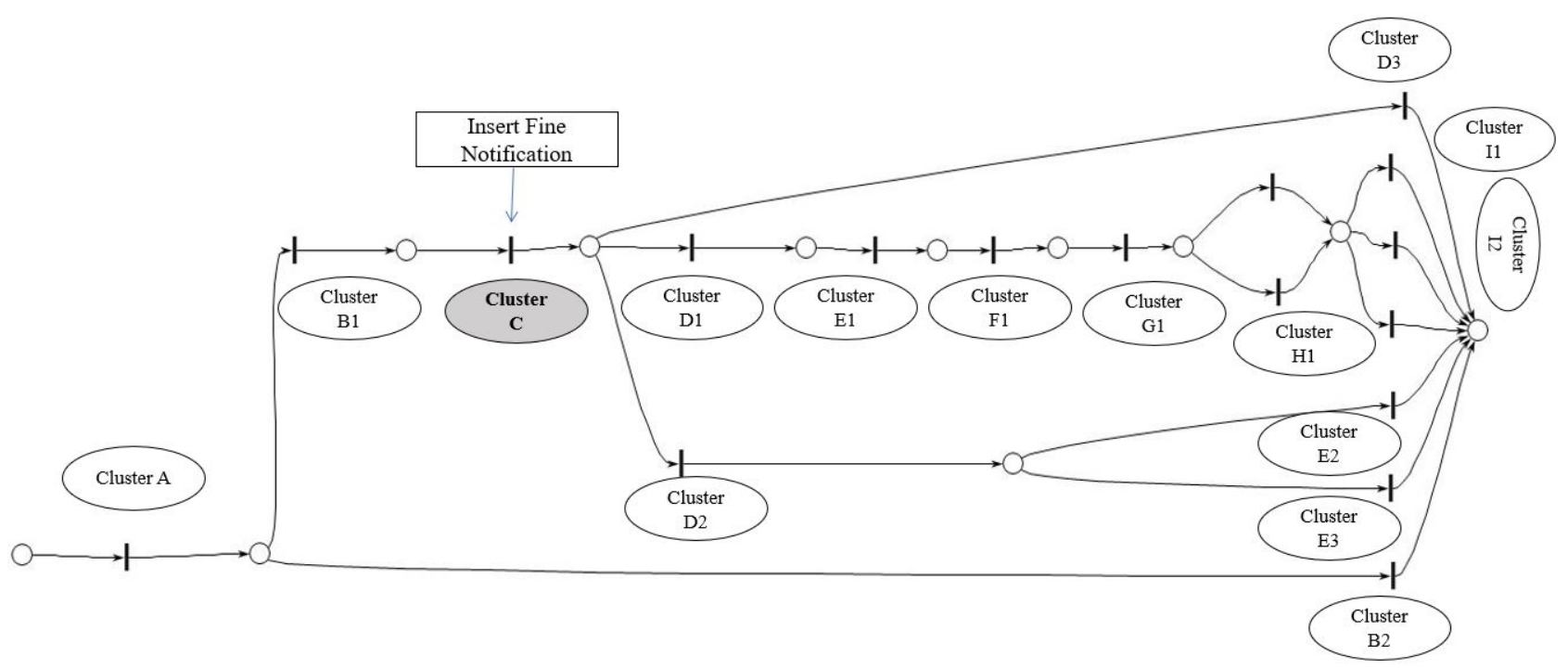

Figure 10. The de facto model with clusters using the social network plug-in

Table 5. Performance of Cluster $\mathrm{C}$ resources

\begin{tabular}{ccccccccc}
\hline Resources & R23 & R35 & R17 & R20 & R301 & R10 & R668 & R53 \\
\hline Sojourn Time & $11,13,12$ & $5,6,4$ & $13,12,6$ & $7,10,8$ & $8,11,15$ & $6,7,19$ & $9,8,10$ & $13,11,17$ \\
\hline Average sojourn time & 12 & 5 & 10 & 8 & 11 & 10 & 9 & 13 \\
\hline
\end{tabular}

average sojourn time (TimeR35 $=5+6+4, \mathrm{R} 35=5$ units). Thus, the resource $\mathrm{R} 35$ executes the insert fine notification activity in an optimal execution time. For instance, we can minimize the business process remaining time by attributing the insert fine notification activity to the resource R35. In this regard, we observe the relationship between predicting events and recommending actions. To do so, recommendations answer to predictions, i.e. we predict that the insert fine notification must be executed in 5 units and by necessity we recommend a resource that will adequately execute this activity in the predicted time boundaries (Cf. Table 5).

To conclude, this example demonstrated the impact of numerical prediction on categorical prediction. In this sense, we used numerical prediction to recommend the suitable resource for executing an activity.

Besides, we urge using more applicative examples. Likewise, more experiments should be designed to test the efficiency and the effectiveness of our proposed approach, through a user evaluation and an assessment of quality based on process mining metrics $[42,43,44]$. However, it is important to apply our approach on event logs known by their variability such as the Sepsis ${ }^{5}$ Event Log and the [45] case study.

\section{Conclusion}

This paper proposes a methodological approach that handles the analysis of unstructured processes through the orchestration of existing process mining activities. Beyond, our

\footnotetext{
${ }^{5} \mathrm{https}: / /$ data.4tu.nl/repository/uuid:915d2bfb-7e84-49ad-a286dc $35 f 063 \mathrm{a} 460$
}

approach describes the application of process mining techniques to treat UBP, from the extraction of a process model based on event data to recommendations at a later stage.

Our approach consists of the following phases: 1-Preparing Normative model (Explore, Discover, Compare, Check, Promote), 2-Detecting violation (Detect), 3-Preparing predictive model and Predicting actions (Predict) 4-Preparing the recommender model and providing Recommendations (Discover, Enhance, Diagnosis, Recommend). In addition, we present an illustrative example for simulating the applicability of our UBP operational support approach. This example is about an UBP of the road traffic fine management.

All in all, the approach proposed here has never been considered elsewhere, to be more specific, it brings new knowledge to the research field in terms of providing a complete scenario of the process mining activities.

As future research, we plan to combine our proposed operational support approach with distributed systems, to take into consideration unstructured business processes in the big data context.

\section{Acknowledgement}

This work was supported by the National Center for Scientific and Technical Research (CNRST) in Rabat, Morocco.

\section{Author contributions}

All authors have contributed equally to the development of this work. 


\section{References}

[1] AALST, W. M. van der. Operational support. In: AALST, W. M. VAN DER. Process mining: Data science in action. 2. ed. Berlin: Springer-Verlag, 2016. cap. 10, p. 301-321.

[2] LAMGHARI, Z. et al. Passage challenges from dataintensive system to knowledge-intensive system related to process mining field. In: ARABWIC ANNUAL INTERNATIONAL CONFERENCE RESEARCH TRACK, 6., 2019, Rabat. Proceedings of the [...]. New York: ACM, 2019. p. 16.

[3] SANCHEZ, E. S. et al. MigraSOA: Migration of legacy web applications to service oriented architectures (SOA). IEEE Latin America Transactions, New York, v. 15, n. 7, p. 1306-1311, 2017.

[4] UNGER, M.; LEOPOLD, H.; MENDLING, J. How much flexibility is good for knowledge intensive business processes: A study of the effects of informal work practices. In: HAWAII INTERNATIONAL CONFERENCE ON SYSTEM SCIENCES, 48., 2015, Kauai. Proceedings of the [...]. Washington: IEEE, 2015. p. 4990-4999.

[5] CICCIO, C. D.; MARREllA, A.; RUSSO, A. Knowledge-intensive processes: characteristics, requirements and analysis of contemporary approaches. Journal on Data Semantics, Berlin, v. 4, n. 1, p. 29-57, 2015.

[6] HASIC, F.; VANWIJCK, L.; VANTHIENEN, J. (Ed.), 1., 2017, Leuven. Integrating Processes, Cases, and Decisions for Knowledge-Intensive Process Modelling. International Workshop on Practicing Open Enterprise Modeling within OMiLAB (PrOse), Aachen: CEUR-WS, 2017. Disponível em: 〈http://ceur-ws.org/Vol-1999/paper2.pdf .

[7] BUIJS, J. Analysing simple and complex processes. In: VERBEEK, ERIC AND BUIJS, JOOS. Introduction to Process Mining with ProM. Eindhoven: Eindhoven University of Technology, 2017. Curso on-line. Disponível em: 〈https://www.futurelearn.com/info/courses/ process-mining/0/steps/15657 .

[8] GÓMEZ, J. C. O. et al. Decision support system for operational risk management in supply chain with 3PL providers. In: ALOR-HERNÁNDEZ, G.; VALENCIAGARCÍA, R. (Ed.). Current Trends on Knowledge-Based Systems. Cham: Springer International Publishing, 2017. (2017, v. 120), p. 205-222.

[9] NAKATUMBA, J.; WESTERGAARD, M.; AALST, W. M. P. v. d. Generating event logs with workload-dependent speeds from simulation models. In: INTERNATIONAL CONFERENCE ON ADVANCED INFORMATION SYSTEMS ENGINEERING, 24., 2012, Gdansk. Proceedings of the [...]. Cham: Springer, 2012. p. 383-397.

[10] BOSE, R. J. C.; AALST, W. M. van der. Discovering signature patterns from event logs. In: IEEE SYMPOSIUM ON COMPUTATIONAL INTELLIGENCE AND DATA MINING, 2013, Singapore. Proceedings of the [...]. New York: IEEE, 2013. p. 111-118.
[11] CONFORTI, R. et al. Supporting risk-informed decisions during business process execution. In: INTERNATIONAL CONFERENCE ON ADVANCED INFORMATION SYSTEMS ENGINEERING, 2013, Kuta. Proceedings of the [...]. Cham: Springer, 2013. p. 116-132.

[12] LEONI, M. D.; AALST, W. M. Van der. The Feature Prediction Package in ProM: Correlating Business Process Characteristics. In: BPM DEMO SESSIONS CO-LOCATED WITH THE 12TH INTERNATIONAL CONFERENCE ON BUSINESS PROCESS MANAGEMENT (BPM 2014), 2014, Eindhoven. Proceedings of the [...]. Aachen: CEUR-WS, 2014. p. 26-30.

[13] HOMPES, B. et al. Discovering deviating cases and process variants using trace clustering. In: BENELUX CONFERENCE ON ARTIFICIAL INTELLIGENCE (BNAIC), 27., 2015, Hasselt. Proceedings of the [...]. BNVKI: Bruxelas, 2015. p. 5-6.

[14] LEONI, M. D.; AALST, W. M. van der; DEES, M. A general process mining framework for correlating, predicting and clustering dynamic behavior based on event logs. Information Systems, Amsterdam, v. 56, p. 235-257, julho de 2015.

[15] MEHDIYEV, N.; EVERMANN, J.; FETTKE, P. A multistage deep learning approach for business process event prediction. In: IEEE CONFERENCE ON BUSINESS INFORMATICS (CBI), 19., 2017, Thessaloniki. Proceedings of the [...]. New York: IEEE, 2017. v. 1, p. 119-128.

[16] FOLINO, F.; FOLINO, G.; PONTIERI, L. An ensemblebased $\mathrm{P} 2 \mathrm{P}$ framework for the detection of deviant business process instances. In: INTERNATIONAL CONFERENCE ON HIGH PERFORMANCE COMPUTING \& SIMULATION (HPCS), 2018, Orléans. Proceedings of the [...]. New York: IEEE, 2018. p. 122-129.

[17] LIN, L.; WEN, L.; WANG, J. MM-Pred: A Deep Predictive Model for Multi-attribute Event Sequence. In: SIAM INTERNATIONAL CONFERENCE ON DATA MINING, 2019, Calgary. Proceedings of the [...]. Philadelphia: SIAM, 2019. p. 118-126.

[18] FRANCESCOMARINO, C. D. et al. Predictive process monitoring methods: Which one suits me best? In: INTERNATIONAL CONFERENCE ON BUSINESS PROCESS MANAGEMENT, 2018, Sydney. Proceedings of the [...]. Cham: Springer, 2018. p. 462-479.

[19] LAMGHARI, Z. et al. Predictive Process Monitoring related to the remaining time dimension: a value-driven framework. In: INTERNATIONAL CONFERENCE ON SMART SYSTEMS AND DATA SCIENCE (ICSSD), 1., 2019, Rabat. Proceeding of the [...]. New York: IEEE, 2019. p. 1-6.

[20] VERENICH, I. et al. Survey and cross-benchmark comparison of remaining time prediction methods in business process monitoring. ACM Transactions on Intelligent Systems and Technology (TIST), New York, v. 10, n. 4, p. 1-34, 2019. 
[21] AALST, W. M. Van der; SCHONENBERG, M. H.; SONG, M. Time prediction based on process mining. Information systems, Amsterdam, v. 36, n. 2, p. 450-475, 2011.

[22] ROUBTSOVA, E. E.; WIERSMA, N. A Practical Extension of Frameworks for Auditing with Process Mining. In: INTERNATIONAL CONFERENCE ON EVALUATION OF NOVEL APPROACHES TO SOFTWARE ENGINEERING 2018, 13., 2018, Funchal. Proceedings of the [...]. Cham: Springer, 2018. p. 406-415.

[23] CHAPELA-CAMPA, D.; MUCIENTES, M.; LAMA, M. Mining frequent patterns in process models. Information Sciences, Amsterdam, v. 472, p. 235-257, janeiro de 2019.

[24] AALST, W. M. Van der et al. ProM: The process mining toolkit. In: BUSINESS PROCESS MANAGEMENT DEMONSTRATION TRACK (BPM DEMOS), 2009, Ulm. Proceedings of the [...]. Aachen: CEUR-WS, 2009. v. 489, p. 1-4.

[25] WEIJTERS, A. J.; AALST, W. M. Van der. Rediscovering workflow models from event-based data using little thumb. Integrated Computer-Aided Engineering, Amsterdam, v. 10, n. 2, p. 151-162, julho de 2003.

[26] GÜNTHER, C. W.; AALST, W. M. V. D. Fuzzy miningadaptive process simplification based on multi-perspective metrics. In: INTERNATIONAL CONFERENCE ON BUSINESS PROCESS MANAGEMENT, 5., 2007, Brisbane. Proceedings of the [...]. Berlin: Springer, 2007. p. 328-343.

[27] POLYVYANYY, A. et al. Maximal structuring of acyclic process models. The Computer Journal, Oxford, v. 57, n. 1, p. 12-35, 2014.

[28] POLATO, M. et al. Data-aware remaining time prediction of business process instances. In: INTERNATIONAL JOINT CONFERENCE ON NEURAL NETWORKS (IJCNN), 2014, Beijing. Proceedings of the [...]. Red Hook: IEEE, 2014. p. 816-823.

[29] OULSNAM, G. The algorithmic transformation of schemas to structured form. The Computer Journal, Oxford, v. 30, n. 1, p. 43-51, 1987.

[30] POLYVYANYY, A.; GARCÍA-BAÑUELOS, L.; DUMAS, M. Structuring acyclic process models. In: INTERNATIONAL CONFERENCE ON BUSINESS PROCESS MANAGEMENT, 8., 2010, Hoboken. Proceedings of the [...]. Berlin: Springer, 2010. v. 6336, p. 276-293.

[31] AUGUSTO, A. et al. Automated discovery of structured process models from event logs: the discover-and-structure approach. Data \& Knowledge Engineering, Amsterdam, v. 117, p. 373-392, abril de 2018.

[32] CARMO, W. C.; ALBUQUERQUE, A. B. O Gerenciamento de projetos apoiado por uma ferramenta de Business Process Management. In: IBERIAN CONFERENCE ON INFORMATION SYSTEMS AND TECHNOLOGIES (CISTI), 9., 2014, Barcelona. Proceedings of the [...]. New York: IEEE, 2014. p. 1-6.
[33] LÜTJE, A.; MÖLLER, A.; WOHLGEMUTH, V. A preliminary concept for an IT-supported industrial symbiosis (IS) tool using extended material flow cost accounting (MFCA) - Impulses for environmental management information systems (EMIS). In: FUCHS-KITTOWSKI, FRANK AND WOHLGEMUTH, VOLKER AND WITTMANN, JOCHEN. Advances and New Trends in Environmental Informatics. Cham: Springer, 2018. p. 167-181.

[34] MANNHARDT, F. et al. Balanced multi-perspective checking of process conformance. Computing, Cham, v. 98, n. 4, p. 407-437, abril de 2016.

[35] MANNHARDT, F. Multi-perspective Process Mining. Tese (Doutorado em Ciência da Computação) — Department of Mathematics and Computer Science, Eindhoven University of Technology, Eindhoven, 2018.

[36] AALST, W. M. P. van der; BOLT, A.; ZELST, S. J. van. RapidProM: mine your processes and not just your data. CoRR, Ithaca, abs/1703.03740, p. 1-25, 2017. Disponível em: 〈http://arxiv.org/abs/1703.03740 .

[37] POLANČIČ, G.; ROZMAN, T. Business process modelling notation. Maribor: Faculty of Electrical Engineering and Computer Science, University of Maribor, 2007.

[38] THOM, L. H. et al. On the capabilities of BPMN for workflow activity patterns representation3. In: INTERNATIONAL WORKSHOP ON BUSINESS PROCESS MODELING NOTATION, 3., 2011, Lucerne. Proceedings of the [...]. Berlin, Heidelberg: Springer, 2011. p. 172-177.

[39] SILVA, B. L. B. et al. An Approach for Reducing the Gap between BPMN Models and Implementation Artifacts. Revista de Informática Teórica e Aplicada, Porto Alegre, v. 16, n. 2, p. 83-86, 2009.

[40] THEIS, J.; DARABI, H. Decay Replay Mining to Predict Next Process Events. IEEE Access, Nova Iorque, v. 7, p. 119787-119803, agosto de 2019.

[41] BOLT, A.; AALST, W. M. van der. Multidimensional process mining using process cubes. In: DANIEL, FLORIAN AND ZUGAL, STEFAN. Enterprise, Business-Process and Information Systems Modeling. Cham: Springer, 2015. v. 214, p. 102-116.

[42] BUIJS, J. C.; DONGEN, B. F. van; AALST, W. M. van der. Quality dimensions in process discovery: The importance of fitness, precision, generalization and simplicity. International Journal of Cooperative Information Systems, Singapura, v. 23, n. 1, p. 1-39, 2014.

[43] JANSSENSWILLEN, G. et al. A comparative study of existing quality measures for process discovery. Information Systems, Amsterdam, v. 71, p. 1-15, junho de 2017.

[44] AVILA, E. et al. Hemogram Data as a Tool for Decisionmaking in COVID-19 Management: Applications to Resource Scarcity Scenarios. arXiv preprint, Cornell, v. 2005.10227, maio de 2020. 
[45] LAMGHARI, Z. et al. Defining business process improvement metrics based on BPM life cycle and process mining techniques. International Journal of Business Process Integration and Management, Geneva, v. 9, n. 2, p. 107$133,2019$. 